\title{
Reduced levels of intracellular calcium releasing in spermatozoa from asthenozoospermic patients Javier Espino* $^{* 1}$, Matías Mediero ${ }^{\dagger 1}$, Graciela M Lozano², Ignacio Bejarano1, Águeda Ortiz ${ }^{2}$, Juan F García ${ }^{2}$, José A Pariente ${ }^{1}$ and Ana B Rodríguez ${ }^{1}$
}

\author{
Address: ${ }^{1}$ Department of Physiology, Faculty of Science, University of Extremadura, Badajoz, Spain and ${ }^{2}$ Extremadura Center of Human Assisted \\ Reproduction, Badajoz, Spain \\ Email: Javier Espino* - jespino@unex.es; Matías Mediero - mathiuss84@hotmail.com; Graciela M Lozano - laoliventina@hotmail.com; \\ Ignacio Bejarano - ibejarano@unex.es; Águeda Ortiz - posagueda@yahoo.es; Juan F García - fcogarciam@sego.es; \\ José A Pariente - pariente@unex.es; Ana B Rodríguez - moratino@unex.es \\ * Corresponding author †Equal contributors
}

Published: 6 February 2009

Reproductive Biology and Endocrinology 2009, 7:11 doi:I0.1186/1477-7827-7-II

This article is available from: http://www.rbej.com/content/7/I/II

(c) 2009 Espino et al; licensee BioMed Central Ltd.

This is an Open Access article distributed under the terms of the Creative Commons Attribution License (http://creativecommons.org/licenses/by/2.0), which permits unrestricted use, distribution, and reproduction in any medium, provided the original work is properly cited.

\begin{abstract}
Background: Asthenozoospermia is one of the most common findings present in infertile males characterized by reduced or absent sperm motility, but its aetiology remains unknown in most cases. In addition, calcium is one of the most important ions regulating sperm motility. In this study we have investigated the progesterone-evoked intracellular calcium signal in ejaculated spermatozoa from men with normospermia or asthenozoospermia.
\end{abstract}

Methods: Human ejaculates were obtained from healthy volunteers and asthenospermic men by masturbation after 4-5 days of abstinence. For determination of cytosolic free calcium concentration, spermatozoa were loaded with the fluorescent ratiometric calcium indicator Fura-2.

Results: Treatment of spermatozoa from normospermic men with 20 micromolar progesterone plus I micromolar thapsigargin in a calcium free medium induced a typical transient increase in cytosolic free calcium concentration due to calcium release from internal stores. Similar results were obtained when spermatozoa were stimulated with progesterone alone. Subsequent addition of calcium to the external medium evoked a sustained elevation in cytosolic free calcium concentration indicative of capacitative calcium entry. However, when progesterone plus thapsigargin were administered to spermatozoa from patients with asthenozoospermia, calcium signal and subsequent calcium entry was much smaller compared to normospermic patients. As expected, pretreatment of normospermic spermatozoa with both the anti-progesterone receptor c262 antibody and with progesterone receptor antagonist RU-38486 decreased the calcium release induced by progesterone. Treatment of spermatozoa with cytochalasin $D$ or jasplakinolide decreased the calcium entry evoked by depletion of internal calcium stores in normospermic patients, whereas these treatments proved to be ineffective at modifying the calcium entry in patients with asthenozoospermia.

Conclusion: Our results suggest that spermatozoa from asthenozoospermic patients present a reduced responsiveness to progesterone. 


\section{Background}

It is well established that calcium signaling plays a pivotal role in sperm physiology, being intimately involved in the regulation of many aspects of mammalian sperm functions [1,2]. Control of motility, including hyperactivation and chemotaxis, is particularly dependent on intracellular free calcium concentration $\left(\left[\mathrm{Ca}^{2+}\right]_{\mathrm{i}}\right)$ signaling in the principal piece of the flagellum and the midpiece [3-5]. In fact, abnormal motility might be explained by abnormally low cytoplasmic calcium $[6,7]$. Furthermore, it has been previously shown that capacitative calcium entry, via transient receptor potential (TRP) channels, may influence human sperm motility [8] and acrosome reaction [9].

Stimulation of human sperm with micromolar doses of progesterone increases $\left[\mathrm{Ca}^{2+}\right]_{\mathrm{i}}$ in a biphasic manner $[10,11]$, since the progesterone-activated signal comprises a transient $\left[\mathrm{Ca}^{2+}\right]_{i}$ 'spike' (of $30-60 \mathrm{~s}$ duration at $37^{\circ} \mathrm{C}$ ) followed by a sustained ramp or plateau. The mechanism by which progesterone elicits a response and subsequent events probably involves its interaction with a cell surface receptor on spermatozoa $[12,13]$. Therefore, the ability of progesterone to generate a response of $\left[\mathrm{Ca}^{2+}\right]_{\mathrm{i}}$ in human spermatozoa has been directly correlated to fertilization success in vitro [14], indicating that this response is biologically important.

Progesterone is present in high (micromolar) concentrations in the follicular fluid $[15,16]$ and is synthesized, both before and after ovulation, by the cells of the cumulus oophorus that surround the egg. Although the ability of progesterone to induce acrosome reaction in mammalian sperm is well established $[17,18]$, it appears that progesterone-induced $\left[\mathrm{Ca}^{2+}\right]_{\mathrm{i}}$ signaling might be involved on the regulation of flagellar activity, modulating motility and/or chemotaxis $[19,20]$. The finding that progesterone is a chemoattractant for human spermatozoa [21] indicates that at least one of the membrane progesterone receptors might act as a chemotaxis receptor [4].

Asthenospermia is a common cause in male infertility characterized by reduced forward motility (WHO grade a+b sperm motility $<50 \%$ or a $<25 \%$ ) or absent sperm motility in fresh ejaculate, but its aetiology remains unknown in most cases. Any alteration in external and internal factors regulating sperm motion and in cellular structure and metabolisms involved in generating tail beat may result in defects in sperm motility and infertility [22]. In the last years, a significant decrease in the percentage of progesterone receptors has been found in men with asthenospermia [23]. In fact, different reports have suggested a relationship between male infertility and the inability of spermatozoa to respond to progesterone in vitro $[24,25]$.
In this paper, we investigated the progesterone-evoked intracellular calcium signal and the role for the actin cytoskeleton in the store-mediated calcium entry in ejaculated spermatozoa from normospermic or asthenospermic men.

\section{Methods \\ Chemicals}

Progesterone, bovine serum albumin (BSA), RPMI-1640 medium, dimethyl BAPTA, RU-38486 and ethylene glycol-bis(2-aminoethylether)- $\mathrm{N}, \mathrm{N}, \mathrm{N}^{\prime}, \mathrm{N}^{\prime}$-tetraacetic acid (EGTA) were from Sigma (Madrid, Spain). Fura-2 acetoxymethyl ester (fura-2/AM) and thapsigargin were from Invitrogen (Barcelona, Spain). Cytochalasin D and jasplakinolide were from Calbiochem (Darmstadt, Germany). Anti-progesterone receptor c262 mouse monoclonal antibody (PR c262) was obtained from Santa Cruz (Santa Cruz Biotechnology, Germany). All others reagents were of analytical grade.

\section{Spermatozoa preparation}

Human semen was obtained from 37 healthy volunteers and 33 asthenozoospermic men at the Extremadura Center of Human Assisted Reproduction (Badajoz, Spain), as approved by local committees and in accordance with the Declaration of Helsinki. This study was approved by the institutional review board of the University of Extremadura and by the ethics committee of the Infantile Hospital (Badajoz, Spain). Each subject was ascertained to be in good health by means of their medical history and a clinical examination including routine laboratory tests and screening. The subjects all were nonsmokers, were not using any medication, and abstained from alcohol. Informed consent was obtained from all patients. Samples were collected by masturbation after 4 or 5 days of sexual abstinence and were allowed to liquefy at $37^{\circ} \mathrm{C}$ for 30 minutes. Semen was washed twice in RPMI medium $(250 \times \mathrm{g}, 10 \mathrm{~min})$, the supernatant was discarded, and the sperm pellet was resuspended in $\mathrm{Na}$ HEPES solution containing the following (in $\mathrm{mM}$ ): $\mathrm{NaCl}$, $140 ; \mathrm{KCl}, 4.7 ; \mathrm{CaCl}_{2}, 1.2 ; \mathrm{MgCl}_{2}, 1.1$; glucose, 10 ; and HEPES, 10 (pH 7.4). The classical semen parameters of spermatozoa concentration, motility, and morphology were examined according to World Health Organization criteria [26]. Sperm concentration and motility were assessed by a computer assisted semen analysis (CASA) system. Our CASA system was based upon analysis of 25 consecutive, digitalized photographic images obtained from a single field at a $200 \times$ magnification on dark field. The percentages of progressive motility were measured. The main criterion for classification of asthenozoospermic men was low sperm motility [27]. Normozoospermia was indicated by a sperm concentration of $\geq 20 \times 10^{6}$ cells $/ \mathrm{mL}$ (mean $\pm \mathrm{SD}=62 \pm 30 \times 10^{6}$ cells $/ \mathrm{mL}$ ), a progressive motility (grade $\mathrm{a}+\mathrm{b}$ sperm motility) $\geq 50 \%$ (mean \pm 
$\mathrm{SD}=54.2 \pm 4.1 \%)$ and a normal sperm morphology $\geq$ $14 \%$ (mean $\pm \mathrm{SD}=17 \pm 3.6 \%)$. Asthenozoospermia was characterised by a sperm concentration of $\geq 20 \times 10^{6}$ cells/ $\mathrm{mL}\left(\right.$ mean $\pm \mathrm{SD}=42 \pm 16 \times 10^{6}$ cells $\left./ \mathrm{mL}\right)$ and a reduced forward motility (grade $\mathrm{a}+\mathrm{b}$ sperm motility) $<50 \%$ (mean $\pm \mathrm{SD}=23.3 \pm 12.2 \%$ ) or absent sperm motility, irrespective of the morphology results.

\section{Measurement of cytosolic free calcium concentration $\left(\left[\mathrm{Ca}^{2+}\right]_{c}\right)$}

Cells were loaded with fura- 2 by incubation with $4 \mu \mathrm{M}$ fura-2 acetoxymethyl ester (Fura-2 AM) for 30 minutes at room temperature, according to a procedure published elsewhere [28]. Once loaded, cells were washed and used within the next 2-4 hours. Fluorescence was recorded from $2 \mathrm{~mL}$ aliquots of magnetically stirred cellular suspension $\left(2 \times 10^{8}\right.$ cells $\left./ \mathrm{mL}\right)$ at $37^{\circ} \mathrm{C}$ by using a Shimadzu spectrofluorophotometer with excitation wavelengths of 340 and $380 \mathrm{~nm}$ and emission at $505 \mathrm{~nm}$. Changes in $\left[\mathrm{Ca}^{2+}\right]_{\mathrm{c}}$ were monitored by using the fura-2 $340 / 380 \mathrm{~nm}$ fluorescence ratio and were calibrated according to the method of Grynkiewicz et al. [29]. In experiments where calcium-free medium is indicated, calcium was omitted and ethylene glycol-bis(2-aminoethylether)-N,N,N',N'tetraacetic acid (EGTA) was added.

Calcium entry and release were estimated using the integral of the rise in $\left[\mathrm{Ca}^{2+}\right]_{\mathrm{c}}$ for $2.5 \mathrm{~min}$ after addition of $\mathrm{CaCl}_{2}$ or progesterone + thapsigargin, respectively [30]. Both calcium entry and release are expressed as nanomolar taking a sample every second $(\mathrm{nM} \cdot \mathrm{s})$, as previously described [31].

\section{Statistical analysis}

Data are expressed as means \pm SD of the numbers of determinations. Analysis of statistical significance was performed by using the Student's $t$-test. $P<0.05$ was considered to indicate a statistically significant difference.

\section{Results}

Asthenozoospermia and intracellular calcium mobilisation In the absence of extracellular calcium (calcium-free medium), fura-2-loaded human spermatozoa were treated with $20 \mu \mathrm{M}$ progesterone plus $1 \mu \mathrm{M}$ thapsigargin. In spite of the fact that the presence of sarcoplasmic-endoplasmic reticulum calcium ATPase (SERCA) in sperm is still debated, we have used thapsigargin, a well-known SERCA inhibitor, to be sure that intracellular calcium stores were not refilled. In this regard, we have previously reported that human platelets possess two separate agonist-releasable calcium stores differentiated by the distinct sensitivity to thapsigargin [32,33]. As shown in Figure 1A, treatment with progesterone and thapsigargin induced a typical transient increase in $\left[\mathrm{Ca}^{2+}\right]_{\mathrm{C}}$ due to calcium release from internal stores in spermatozoa from normospermic men. However, when progesterone plus thapsigargin were administered to spermatozoa from patients with asthenozoospermia, calcium signal was much smaller compared to calcium signal obtained in spermatozoa from normospermic men (Figure 1B). Similar results were obtained when spermatozoa were treated with progesterone alone (insets Fig. 1A and 1B) The integral of the rise in $\left[\mathrm{Ca}^{2+}\right]_{\mathrm{c}}$ above basal for $2.5 \mathrm{~min}$ after addition of progesterone plus thapsigargin taking data every second were 13072.7 \pm 697.1 and $5926.5 \pm 475.3 \mathrm{nM} \cdot \mathrm{s}$ in normospermic and asthenozoospermic men, respectively (Figure $1 \mathrm{C} ; \mathrm{n}=7 ; \mathrm{P}$ $<0.05$ ). In addition, spermatozoa were loaded with dimethyl BAPTA, an intracellular calcium chelator, by incubating the cells for 30 minutes at $37^{\circ} \mathrm{C}$ with $10 \mu \mathrm{M}$ dimethyl BAPTA-AM. As expected, dimethyl BAPTA loading prevented progesterone-evoked $\left[\mathrm{Ca}^{2+}\right]_{C}$ elevations in both normospermic (Figure 1A) and asthenozoospermic (Figure $1 \mathrm{~B})$ men.

Moreover, we evaluated the effect of $20 \mu \mathrm{M}$ progesterone on progressive sperm motility measured by CASA system after 30 min of incubation. The treatment with progesterone caused a significant increase in the percentage of progressive motility in human spermatozoa from normospermic patients $(54.2 \pm 4.1$ and $70.5 \pm 2.3 \%$ in untreated and progesterone-treated spermatozoa, respectively), whereas progesterone was unable to modify the motility in spermatozoa from asthenozoospermic patients $(23.3 \pm 12.2$ and $27.5 \pm 10.3 \%$ in untreated and progesterone-treated spermatozoa, respectively).

Figure 2A demonstrates that the increase of $\left[\mathrm{Ca}^{2+}\right]_{\mathrm{c}}$ induced by progesterone plus thapsigargin was also observed in the presence of extracellular calcium $\left(\left[\mathrm{Ca}^{2+}\right]_{0}\right.$ $=1.2 \mathrm{mM}$ ). In addition, we tested if progesterone receptor antibodies or antagonists would reverse the stimulatory effects of progesterone on calcium signal in normospermic spermatozoa. Preincubation of fura-2 loaded spermatozoa from normospermic patients with both the antiprogesterone receptor c262 antibody (PR c262) (1:10, final concentration $100 \mu \mathrm{g} / \mathrm{ml}$ ) and the progesterone receptor antagonist RU-38486 $(50 \mu \mathrm{M})$ for 30 min significantly reduced the progesterone-induced calcium release (Figure 2B). This clearly demonstrates that the blockade of progesterone receptors reduces the calcium mobilization induced by progesterone, and therefore normospermic spermatozoa behave as asthenozoospermic-like spermatozoa.

Interestingly, subsequent addition of calcium $(300 \mu \mathrm{M})$ to the suspension of progesterone plus thapsigargin-treated spermatozoa resulted in a detectable increase in $\left[\mathrm{Ca}^{2+}\right]_{\mathrm{C}}$ indicative of calcium entry (Figure 3A). Similarly, subsequent calcium entry was significantly reduced $(P<0.05)$ in comparison to normospermic patients (Figure $3 \mathrm{~A}$ ). The 

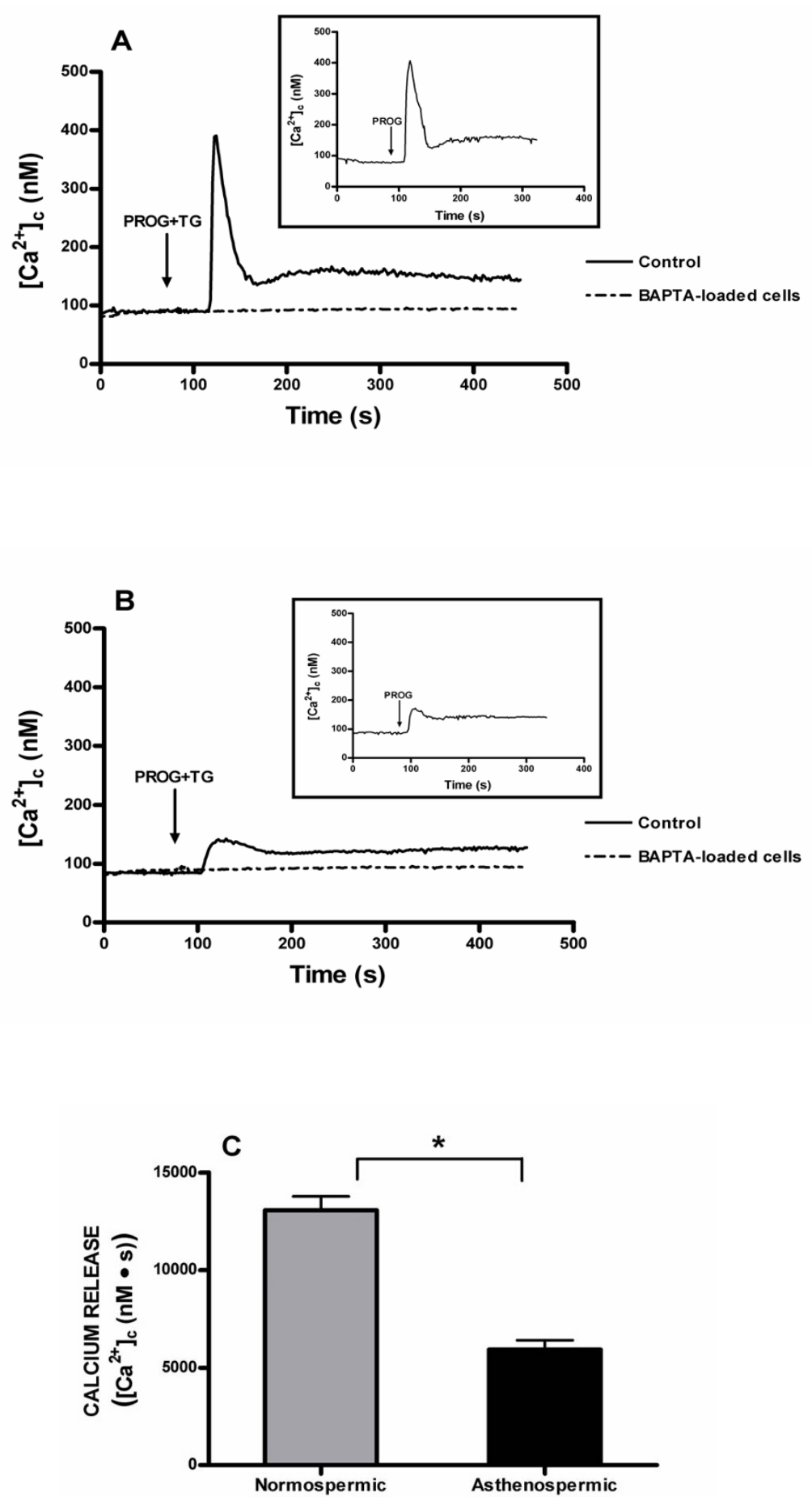

Figure I

Mobilization of calcium in response to progesterone in human spermatozoa from normospermic or asthenozoospermic patients. Fura-2-loaded human spermatozoa from normospermic $(A)$ or asthenozoospermic $(B)$ patients were stimulated with $20 \mu \mathrm{M}$ progesterone alone (PROG) (insets) or plus I $\mu \mathrm{M}$ thapsigargin (TG) in calcium-free solution (+ I mM EGTA), in the absence (control) or presence of dimethyl BAPTA ( $10 \mu M$ for $30 \mathrm{~min}$ ). Traces are representative of five independent experiments. (C) Histogram represents the integral for 2.5 min of the calcium release, in normospermic and asthenozoospermic patients, calculated as described in Methods section. Values are means \pm SD of five independent experiments. $* P<$ 0.05 . 

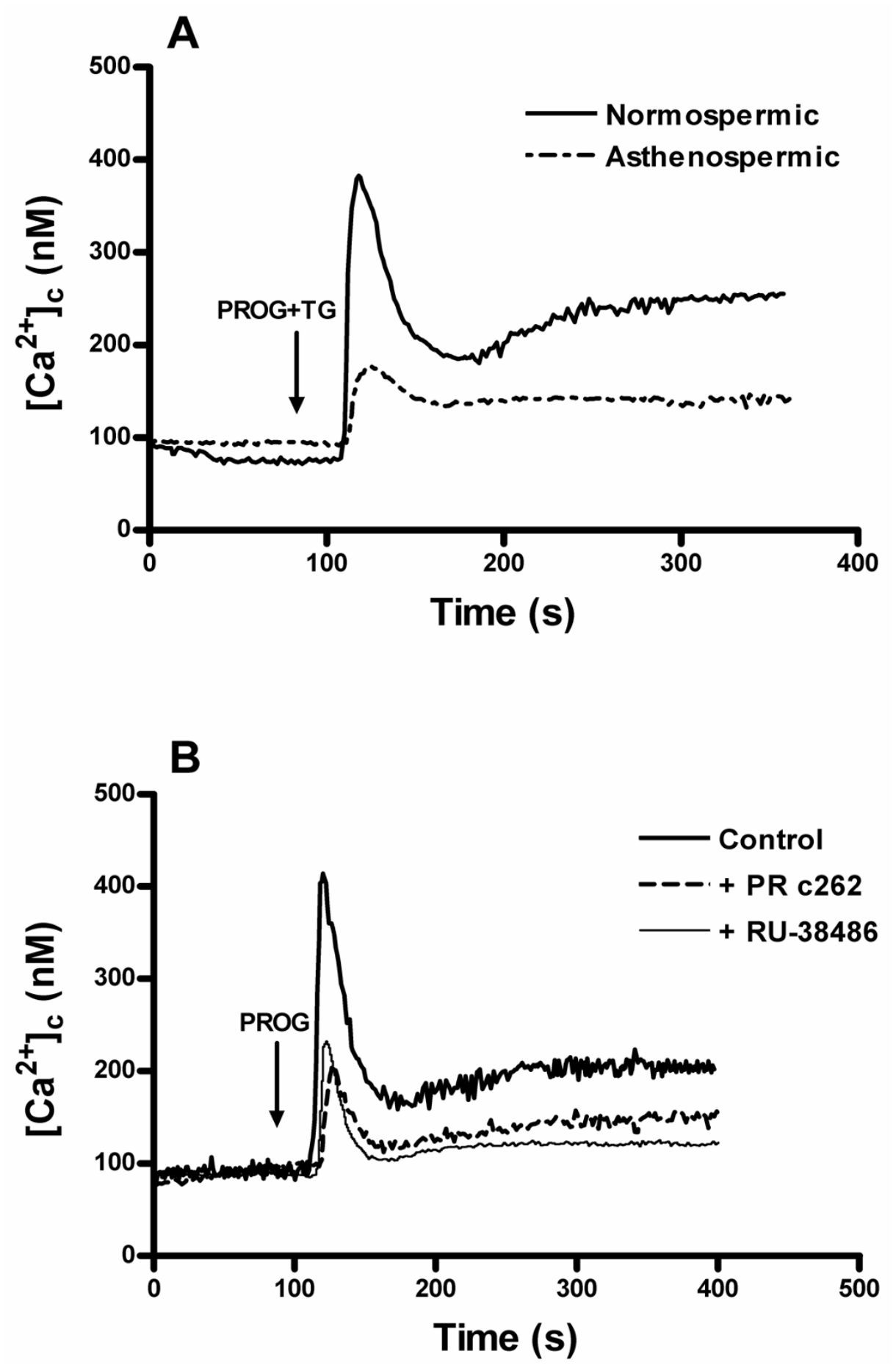

Figure 2

Effect of the blockade of progesterone receptor on calcium mobilization evoked by progesterone in human spermatozoa. (A) Fura-2-loaded human spermatozoa from normospermic and asthenozoospermic patients were stimulated with $20 \mu \mathrm{M}$ progesterone (PROG) plus I $\mu \mathrm{M}$ thapsigargin (TG) in a calcium-normal solution (I.2 $\left.\mathrm{mM}\left[\mathrm{Ca}^{2+}\right]_{0}\right)$. (B) Fura-2loaded human spermatozoa from normospermic patients were pretreated with the anti-progesterone receptor c262 antibody (PR c262) (I:I0, final concentration $100 \mu \mathrm{g} / \mathrm{ml}$ for $30 \mathrm{~min}$ ) or the progesterone receptor antagonist RU-38486 (50 $\mu$ M for 30 $\mathrm{min}$ ) and then stimulated with $20 \mu \mathrm{M}$ progesterone (PROG) in a calcium-normal solution (I.2 $\left.\mathrm{mM}\left[\mathrm{Ca}^{2+}\right]_{0}\right)$. Traces are representative of 3-4 independent experiments. 

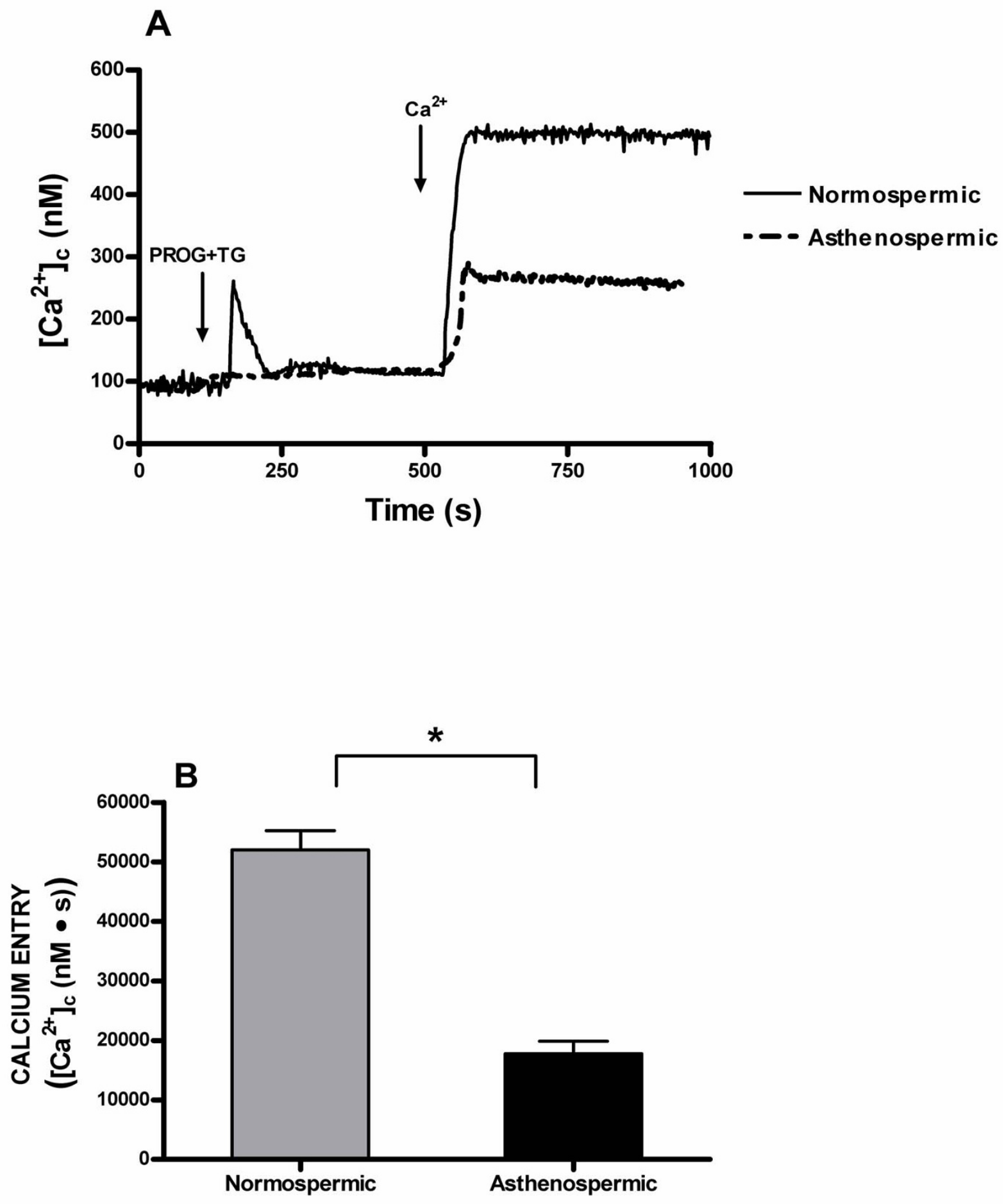

Figure 3

Progesterone induced calcium entry in human spermatozoa from normospermic or asthenozoospermic patients. (A) Fura-2-loaded human spermatozoa were treated with $20 \mu \mathrm{M}$ progesterone (PROG) plus I $\mu$ M thapsigargin (TG) for $6 \mathrm{~min}$ in a calcium-free medium (+ $100 \mu \mathrm{M}$ EGTA) followed by addition of $\mathrm{CaCl}_{2}(300 \mu \mathrm{M})$ to initiate calcium entry. Traces are representative of seven independent experiments. (B) Histogram represents the integral for 2.5 min of the amount of calcium entry, in normospermic and asthenozoospermic patients, calculated as described in Methods section. Values are means \pm SD of seven independent experiments. $* p<0.05$. 
integral of the rise in $\left[\mathrm{Ca}^{2+}\right]_{\mathrm{c}}$ above basal for $2.5 \mathrm{~min}$ after addition of calcium taking data every second were $52003.2 \pm 3219.4$ and $17770.3 \pm 2084.1 \mathrm{nM} \cdot \mathrm{s}$ in normospermic and asthenozoospermic patients, respectively (Figure 3B; $\mathrm{n}=7 ; \mathrm{P}<0.05$ ).

\section{Effect of cytochalasin D and jasplakinolide on capacitative calcium entry in spermatozoa}

Cytochalasin D, a widely utilized membrane-permeant inhibitor of actin polymerization which binds to the barbed end of actin filaments [34], and jasplakinolide, a cell-permeant peptide isolated from Jaspis johnstoni which induces polymerization and stabilization of actin filaments in vitro, but in vivo it can disrupt actin filaments and induce polymerization of monomeric actin into amorphous masses [35,36], are useful tools to further study the role of the actin cytoskeleton in store-mediated calcium entry. As shown in Figure 4A, pretreatment of human spermatozoa with both $10 \mu \mathrm{M}$ cytochalasin $\mathrm{D}$ for $40 \mathrm{~min}$ and $10 \mu \mathrm{M}$ jasplakinolide for $30 \mathrm{~min}$ at room temperature significantly diminished $(\mathrm{p}<0.05)$ calcium entry evoked by depletion of internal calcium stores induced by progesterone plus thapsigargin in normospermic patients. The integral of the rise in $\left[\mathrm{Ca}^{2+}\right]_{\mathrm{c}}$ above basal for $2.5 \mathrm{~min}$ after addition of calcium taking data every second were $28842.4 \pm 2519.3$ and $36256.1 \pm 3129.7 \mathrm{nM} \cdot \mathrm{s}$ in spermatozoa treated with cytochalasin $\mathrm{D}$ or jasplakinolide, respectively (Figure $4 \mathrm{~B} ; \mathrm{n}=7 ; \mathrm{P}<0.05$ ).

However, these treatments proved to be ineffective at modifying calcium entry in patients with asthenozoospermia (Figure 5A). The integral of the rise in $\left[\mathrm{Ca}^{2+}\right]_{\mathrm{c}}$ above basal for $2.5 \mathrm{~min}$ after addition of calcium taking data every second were $20556.1 \pm 2521.6$ and $17175.3 \pm$ $1624.9 \mathrm{nM} \cdot \mathrm{s}$ in spermatozoa treated with cytochalasin D or jasplakinolide, respectively (Figure $5 \mathrm{~B} ; \mathrm{n}=7$ ), which closely suggest that cytochalasin D and jasplakinolide are unable to affect the calcium entry evoked by depletion of intracellular calcium pools induced by progesterone plus thapsigargin in asthenozoospermic spermatozoa.

\section{Discussion}

Progesterone, the most-studied and best-characterized calcium-mobilizing agonist of human sperm, caused a biphasic increase in $\left[\mathrm{Ca}^{2+}\right]_{c}$ from healthy donors as reported previously $[18,28,37]$. In addition, progesteroneinduced $\left[\mathrm{Ca}^{2+}\right]_{\mathrm{C}}$ transient showed very little sensitivity to the SERCA-inhibitor thapsigargin, since thapsigargin by itself had a negligible effect on calcium release from intracellular stores (Espino et al., unpublished observations). These findings are consistent with previous reports in human ejaculated spermatozoa $[38,39]$ indicating that SERCAs do not contribute significantly to refill the progesterone-mobilized calcium store [37]. In addition, we cannot reject the involvement of secretory pathway calcium
ATPase (SPCA), which is expressed in spermatozoa and mainly targeted to Golgi apparatus [40]. In fact, this nonSERCA store calcium-ATPase has been reported to be important in regulating $\left[\mathrm{Ca}^{2+}\right]_{\mathrm{i}}[38]$.

Furthermore, our results have shown that capacitative calcium-influx occurs in sperm from normospermic men, which is consistent with a number of previous studies in sperm $[8,11,39,41]$. In the last years, capacitative calcium entry seems to be involved in the regulation of sperm motility, indicating that extracellular calcium plays a pivotal role in sperm motility $[7,37]$.

In asthenozoospermic men, we have found that progesterone-induced calcium transient was undetectable and subsequent calcium entry was much smaller compared to normospermic patients. In addition, progesteroneinduced calcium release in normospermic spermatozoa pretreated with both PR c262 and the progesterone receptor antagonist RU-38486 was similar to that obtained in spermatozoa from asthenozoospermic patients. This findings could be explained either by failure to localise a calcium signal to its site of action or by reduced or absent expression of progesterone receptors $[23,42,43]$. The reduced responsiveness to progesterone we found in sperm from asthenozoospermic subjects can be mainly due to decreased levels on membrane progesterone receptors, which could be translated in abnormal calcium signaling, and probably not to a direct effect on calcium release process. In fact, previous studies have reported a significant decrease in the percentage of progesterone receptors in asthenozoospermic men [23], and disturbance in the expression of membrane progesterone receptors might be involved in male infertility [44]. In addition, our results are in agreement with previous reports and suggest a strong relationship between calcium homeostasis, sperm motility, and male infertility. In fact, both reduced calcium/calmodulin (CaM) complex and intracellular calcium levels have been demonstrated in asthenozoospermic patients $[45,46]$. Moreover, different calcium channelopaties have been described for sperm calciumpermeable channels in asthenozoospermic patients $[47,48]$.

On the other hand, both cytochalasin $\mathrm{D}$, a widely used membrane-permeant inhibitor of actin polymerization, and jasplakinolide, a cell-permeant peptide which reorganizes actin filaments into a tight cortical layer adjacent to the plasma membrane $[35,36]$, significantly reduced activation of store-mediated calcium entry in spermatozoa from normospermic men. These results suggest that vesicular trafficking might play an important role in storeoperated calcium entry. Similar results have been previously obtained in both pancreatic acinar cells [49] and human platelets [50] when cells were stimulated with 

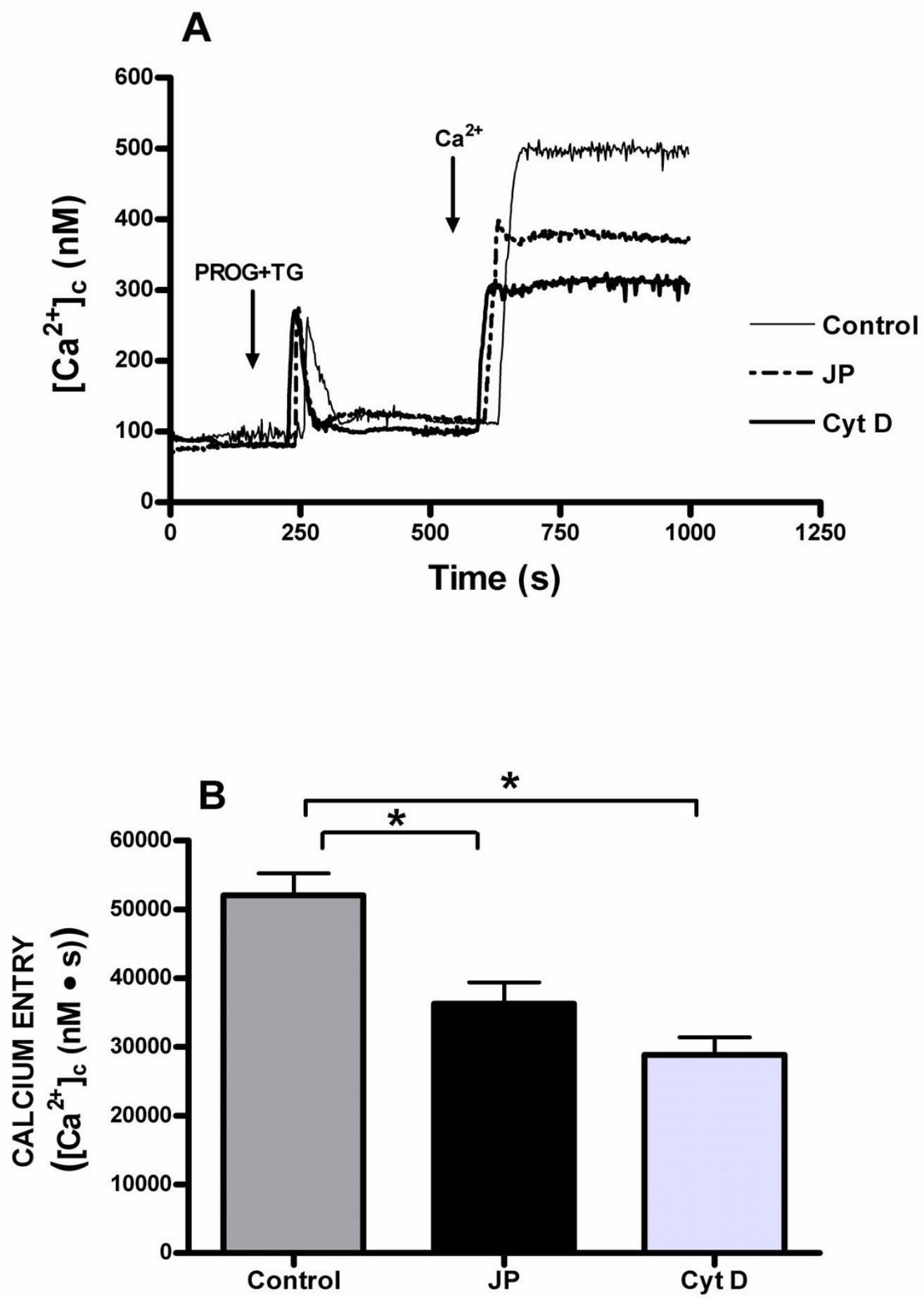

Figure 4

Effects of cytochalasin D and jasplakinolide on progesterone induced calcium entry in human spermatozoa from normospermic patients. (A) Fura-2-loaded human spermatozoa were preincubated at room temperature in the presence of $10 \mu \mathrm{M}$ cytochalasin (Cyt D) for 40 min or $10 \mu \mathrm{M}$ jasplakinolide (JP) for 30 min. Cells were then stimulated with $20 \mu \mathrm{M}$ progesterone (PROG) plus I $\mu$ M thapsigargin (TG) in calcium-free medium (+ $100 \mu \mathrm{M} \mathrm{EGTA),} \mathrm{and} 6$ min later $\mathrm{CaCl}_{2}(300 \mu \mathrm{M})$ was added to the medium to initiate calcium entry. Traces are representative of seven independent experiments. (B) Histogram represents the integral for $2.5 \mathrm{~min}$ of the amount of calcium entry, calculated as described in Methods section. Values are means \pm SD of seven independent experiments. $* P<0.05$. 

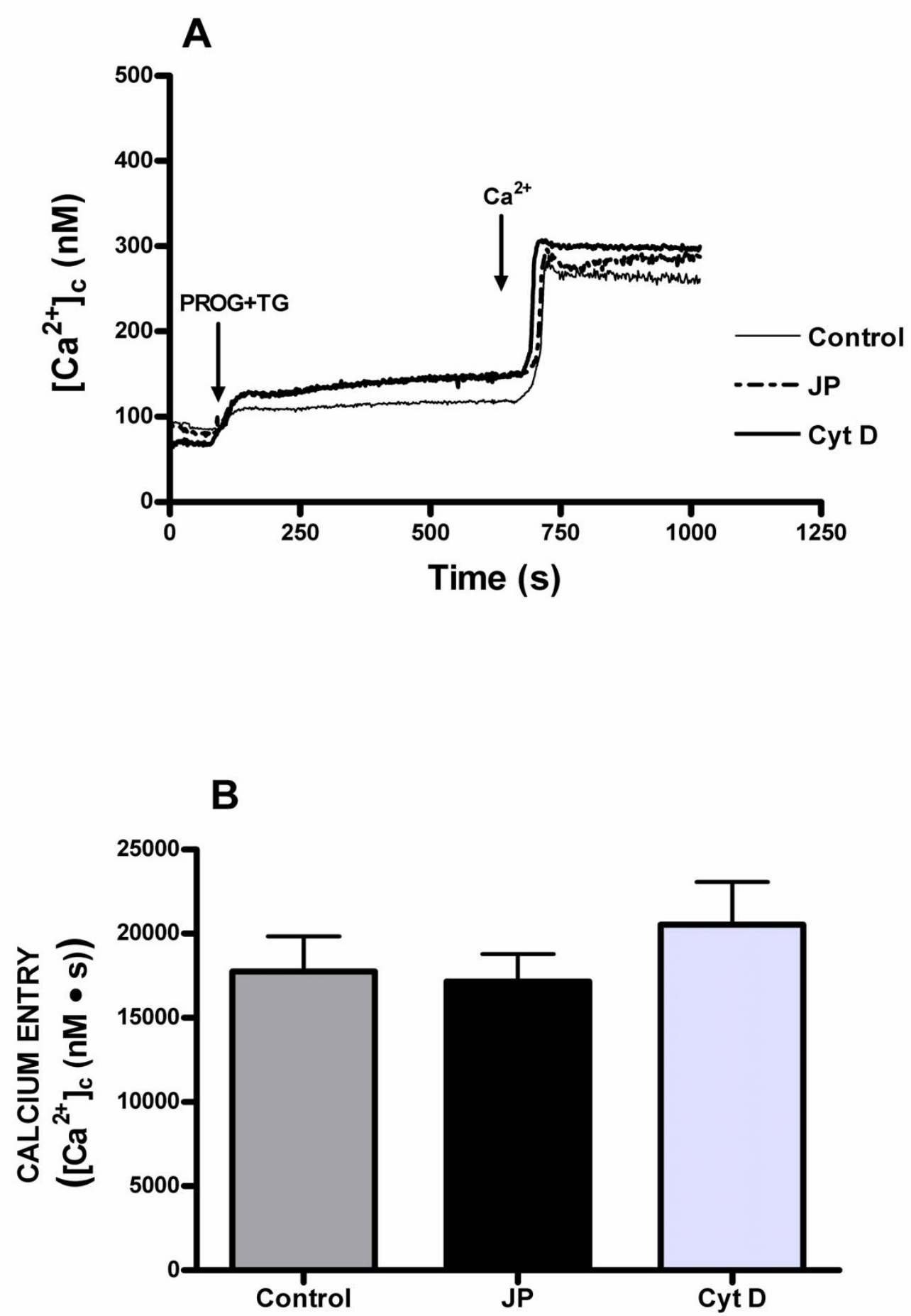

Figure 5

Effects of cytochalasin D and jasplakinolide on progesterone induced calcium entry in human spermatozoa from asthenozoospermic patients. (A) Fura-2-loaded human spermatozoa were preincubated at room temperature in the presence of $10 \mu \mathrm{M}$ cytochalasin D (Cyt D) for 40 min or $10 \mu \mathrm{M}$ jasplakinolide (JP) for 30 min. Cells were then stimulated with

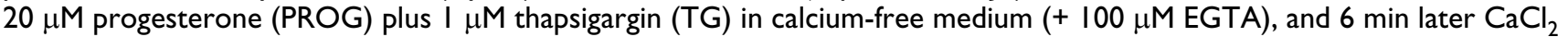
$(300 \mu \mathrm{M})$ was added to the medium to initiate calcium entry. Traces are representative of seven independent experiments. (B) Histogram represents the integral for 2.5 min of the amount of calcium entry, in control, Cyt D-treated and JP-treated spermatozoa, calculated as described in Methods section. Values are means \pm SD of seven independent experiments. 
cholecystokinin or thrombin, respectively. These authors showed that disruption of actin cytoskeleton by cytochalasin $\mathrm{D}$ or stabilization of cortical actin barrier by jasplakinolide prevented the activation of store-mediated calcium entry, suggesting that actin cytoskeleton plays an important role in store-mediated calcium entry $[49,50]$.

\section{Conclusion}

Our results show that spermatozoa from asthenozoospermic patients present a reduced responsiveness to progesterone. We presume that disrupted calcium mobilization in spermatozoa from this group of patients might be associated with lower sperm motility and reduction of reproductive ability of these donors. Further studies are required to determine molecular mechanisms responsible for decreased progesterone-evoked intracellular calcium signal in spermatozoa from asthenozoospermic men.

\section{Abbreviations}

$\left[\mathrm{Ca}^{2+}\right]_{\mathrm{c}}$ : cytosolic free $\mathrm{Ca}^{2+}$ concentration; $\left[\mathrm{Ca}^{2+}\right]_{\mathrm{i}}$ : intracellular free $\mathrm{Ca}^{2+}$ concentration; Cyt $\mathrm{D}$ : cytochalasin $\mathrm{D}$; EGTA: ethylene glycol-bis(2-aminoethylether)-N,N,N',N'tetraacetic acid; JP: jasplakinolide; PR c262: anti-progesterone receptor c262 antibody; TG: thapsigargin

\section{Competing interests}

The authors declare that they have no competing interests.

\section{Authors' contributions}

JE and MM carried out the experiments and wrote the manuscript. GML, AO and JFG collected sperm samples and carried out the analysis of sperm parameters. IB performed the statistical analysis and helped to write the manuscript. JAP and ABR conceived of the study, designed the experiments and discussed the results. All authors read and approved the final manuscript.

\section{Acknowledgements}

This work was supported by Merck Farma y Química, S.L. (Merck-Serono). JE and IB are supported by Fundación Salud 2000 and Junta de Extremadura (PRE06070) fellowships, respectively.

\section{References}

I. Felix R: Molecular physiology and pathology of $\mathrm{Ca}^{2+}$-conducting channels in the plasma membrane of mammalian sperm. Reproduction 2005, I 29:25I-262.

2. Jimenez-Gonzalez C, Michelangeli F, Harper CV, Barratt CL, Publicover SJ: Calcium signalling in human spermatozoa: $A$ specialized 'toolkit' of channels, transporters and stores. Hum Reprod Update 2006, I 2:253-267.

3. Yanagimachi R: Fertility of mammalian spermatozoa: Its development and relativity. Zygote 1994, 2:37I-372.

4. Eisenbach M, Giojalas LC: Sperm guidance in mammals - an unpaved road to the egg. Nat Rev Mol Cell Biol 2006, 7:276-285.

5. Publicover SJ, Giojalas LC, Teves ME, de Oliveira GS, García AA, Barratt $\mathrm{CL}$, Harper $\mathrm{CV}: \mathrm{Ca}^{2+}$ signalling in the control of motility and guidance in mammalian sperm. Front Biosci 2008, 13:5623-5637.

6. Luconi M, Baldi E: How do sperm swim? Molecular mechanisms underlying sperm motility. Cell Mol Biol 2003, 49:357-369.
7. Marquez B, Ignotz G, Suarez SS: Contributions of extracellular and intracellular $\mathrm{Ca}^{2+}$ to regulation of sperm motility: release of intracellular stores can hyperactivate CatSperI and CatSper2 null sperm. Dev Biol 2007, 303(SuppI I):2 I4-22I.

8. Castellano LE, Trevino CL, Rodriguez D, Serrano CJ, Pacheco J, Tsutsumi $V$, Felix $R$, Darszon A: Transient receptor potential (TRPC) channels in human sperm: expression, cellular localization and involvement in the regulation of flagellar motility. FEBS Lett 2003, 541:69-74.

9. Rossato M, Di Virgilio F, Rizzuto R, Galeazzi C, Foresta C: Intracellular calcium store depletion and acrosome reaction in human spermatozoa: Role of calcium and plasma membrane potential. Mol Hum Reprod 200I, 7:1 19-128.

10. Kirkman-Brown JC, Punt EL, Barratt CL, Publicover SJ: Zona pellucida and progesterone-induced $\mathrm{Ca}^{2+}$ signaling and acrosome reaction in human spermatozoa. J Androl 2002, 23:306-3I 5.

II. Bedu-Addo K, Barratt CL, Kirkman-Brown JC, Publicover SJ: Patterns of $\left[\mathrm{Ca}^{2+}\right]_{(i)}$ mobilization and cell response in human spermatozoa exposed to progesterone. Dev Biol 2007, 302:324-332.

12. Blackmore PF, Beebe SJ, Danforth DR, Alexander N: Progesterone and $17 \alpha$-hydroxyprogesterone: novel stimulators of calcium influx in human sperm. I Biol Chem 1990, 265:1376-1380.

13. Blackmore PF, Im WB, Bleasdale JE: The cell surface progesterone receptor which simulates influx in human sperm is unlike the $A$ ring reduced steroid site on the $\mathrm{GABA}_{\mathrm{A}}$ receptor/chloride channel. Mol Cell Endocrinol 1994, 104:237-243.

14. Krausz C, Bonaccorsi L, Maggio P, Luconi M, Criscuoli L, Fuzzi B, Pellegrini $S$, Forti $G$, Baldi $E$ : Two functional assays of sperm responsiveness to progesterone and their predictive values in in-vivo fertilisation. Human Reprod 1996, I I:166I-1667.

15. Osman RA, Andria ML, Jones AD, Meizel S: Steroid induced exocytosis: the human sperm acrosome reaction. Biochem Biophys Res Commun 1989, 160:828-833.

16. Thomas P, Meizel S: Phosphatidylinositol 4,5-bisphosphate hydrolysis in human sperm stimulated with follicular fluid or progesterone is dependent upon $\mathbf{C a}^{2+}$ influx. Biochem J 1989, 264:539-546.

17. Baldi E, Luconi M, Bonaccorsi L, Fonti G: Nongenomic effects of progesterone on spermatozoa: mechanisms of signal transduction and clinical implications. Front Biosci 1998, 3: I05 I- 1059.

18. Harper CV, Kirkman-Brown JC, Barratt CL, Publicover SJ: Encoding of progesterone stimulus intensity by intracellular $\left[\mathrm{Ca}^{2+}\right]$ $\left(\left[\mathrm{Ca}^{2+}\right]_{i}\right)$ in human spermatozoa. Biochem $J$ 2003, 372:407-417.

19. Uhler ML, Leung A, Chan SY, Wang C: Direct effects of progesterone and antiprogesterone on human sperm hyperactivated motility and acrosome reaction. Fertil Steril 1992, 58: $1191-1198$.

20. Jaiswal BS, Tur-Kaspa I, Dor J, Mashiach S, Eisenbach M: Human sperm chemotaxis: Is progesterone a chemoattractant? Bio. Reprod 1999, 60:1314-1319.

21. Teves ME, Barbano F, Guidobaldi HA, Sánchez R, Miska W, Giojalas LC: Progesterone at the picomolar range is a chemoattractant for mammalian spermatozoa. Fertil Steril 2006, 86:745-749.

22. Curi SM, Ariagno JI, Chenlo PH, Mendeluk GR, Pugliese MN, Sardi Segovia LM, Repetto HE, Blanco AM: Asthenozoospermia: analysis of a large population. Arch Androl 2003, 49:343-349.

23. Gadkar S, Shah CA, Sachdeva G, Samant U, Puri CP: Progesterone receptor as an indicator of sperm function. Biol Reprod 2002, 67:1327-1336.

24. Krausz C, Bonaccorsi L, Luconi M, Fuzzi B, Criscuoli L, Pellegrini S, Forti G, Baldi E: Intracellular calcium increase and acrosome reaction in response to progesterone in human spermatozoa are correlated with in vitro fertilization. Hum Reprod 1995, 10:122-124.

25. Falsetti C, Baldi E, Krausz C, Casono R, Failli P, Forti G: Decreased responsiveness to progesterone of spermatozoa in oligozoospermic patients. J Androl 1993, 14:17-22.

26. World Health Organization: WHO laboratory manual for the examination of human semen and semen-cervical mucus interaction 4th edition. New York: Cambridge University Press; 1999.

27. Curi S, Ariagno J, Repetto H, Chenlo P, Mendeluk G, Pugliese N, Sardi $M$, Blanco A: Laboratory methods for the diagnosis of asthenozoospermia. Arch Androl 2002, 48: 177-I80.

28. Bejarano I, Lozano GM, Ortiz A, García JF, Paredes SD, Rodríguez AB, Pariente JA: Caspase 3 activation in human spermatozoa in 
response to hydrogen peroxide and progesterone. Fertil Steril 2008, 90: I340-1347.

29. Grynkiewicz G, Poenie M, Tsien RY: A new generation of $\mathbf{C a}^{2+}$ indicators with greatly improved fluorescence properties. Biol Chem 1985, 260:3440-3450.

30. Rosado JA, Jenner S, Sage SO: A role for the actin cytoskeleton in the initiation and maintenance of stored-mediated calcium entry in human platelets. Evidence for conformational coupling. I Biol Chem 2000, 275:7527-7533.

31. Heemskerk JW, Feijge MA, Henneman L, Rosing J, Hemker HC: The $\mathrm{Ca}^{2+}$-mobilizing potency of alpha-thrombin and thrombinreceptor-activating peptide on human platelets - concentration and time effects of thrombin-induced $\mathbf{C a}^{2+}$ signalling. Eur J Biochem 1997, 249:547-555.

32. Jardin I, Ben Amor N, Bartegi A, Pariente JA, Salido GM, Rosado JA: Differential involvement of thrombin receptors in $\mathrm{Ca}^{2+}$ release from two different intracellular stores in human platelets. Biochem / 2007, 40 I:167-174.

33. López JJ, Camello-Almaraz C, Pariente JA, Salido GM, Rosado JA: $\mathrm{Ca}^{2+}$ accumulation in acidic organelles mediated by $\mathrm{Ca}^{2+}$ and vacuolar $\mathbf{H}^{+}$-ATPases in human platelets. Biochem J 2005, 390:243-252.

34. Fox JE, Phillips DR: Inhibition of actin polymerization in blood platelets by cytochalasins. Nature 198I, 292:650-652.

35. Bubb MR, Senderowicz AM, Sausville EA, Dunacan KL, Korn ED: Jasplakinolide, a cytotoxic natural product, induces actin polymerization and competitively inhibits the binding of phalloidin to F-actin. J Biol Chem I994, 269: I 4869- I487|

36. Bubb MR, Spector I, Beyer BB, Fosen KM: Effects of jasplakinolide on the kinetics of actin polymerization. An explanation for certain in vivo observations. A Biol Chem 2000, 275:5 I63-5I70.

37. Bedu-Addo K, Costello S, Harper C, Machado-Oliveira G, Lefievre L, Ford C, Barrat C, Publicover S: Mobilisation of the stored calcium in the neck region of the human sperm - a mechanism for regulation of flagellar activity. Int J Dev Biol 2008, 52:6 I5-626.

38. Harper CV, Barratt CL, Publicover SJ: Stimulation of human spermatozoa with progesterone gradients to simulate approach to the oocyte. Induction of $\left[\mathrm{Ca}^{2+}\right]_{\mathrm{i}}$ oscillations and cyclical transitions in flagellar beating. I Biol Chem 2004, 279:463।5-46325.

39. Harper C, Wootton L, Michelangeli F, Lefievre L, Barratt C, Publicover S: Secretory pathway $\mathrm{Ca}^{2+}$-ATPase (SPCAI) $\mathrm{Ca}^{2+}$ pumps, not SERCAs, regulate complex $\left[\mathrm{Ca}^{2+}\right]_{(\mathrm{i})}$ signals in human spermatozoa. J Cell Sci 2005, I 18:1673-1685.

40. Wuytack F, Raeymaekers L, Missiaen L: PMRI/SPCA Ca ${ }^{2+}$ pumps and the role of Golgi apparatus as a $\mathbf{C a}^{2+}$ store. Pflugers Arch 2003, 446: I 48-I 53.

4I. Blackmore PF: Thapsigargin elevates and potentiates the ability of progesterone to increase intracellular free calcium in human sperm: Possible role of perinuclear calcium. Cell Calcium 1993, I 4:53-60.

42. Berridge MJ: Remodelling $\mathbf{C a}^{2+}$ signalling systems and cardiac hypertrophy. Biochem Soc Trans 2006, 34:228-23I.

43. Petersen $\mathrm{OH}$, Sutton $\mathrm{R}$, Criddle DN: Failure of calcium microdomain generation and pathological consequences. Cell Calcium 2006, 40:593-600

44. Kotwicka M, Warchol JB: Expression of progesterone membrane receptor in spermatozoa from normospermic and oligozoospermic men. Folia Histochem Cytobiol 200I, 39: I39- 140.

45. Martínez RR, Luna M, Chavarria ME: Concentrations of calmodulin in sperm in relation to their motility in fertile euspermic and infertile asthenozoospermic men. Int J Androl 1987, 10:507-515.

46. Meseguer M, Garrido N, Martínez-Conejero JA, Simón C, Pellicer A Remohí J: Relationship between standard semen parameters, calcium, cholesterol contents and mitochondrial activity in ejaculated spermatozoa from fertile and infertile males. Assist Reprod Genet 2004, 2 I:445-45 I.

47. Avidan N, Tamary H, Dgany O, Cattan D, Pariente A, Thulliez M, Borot N, Moati L, Barthelme A, Shalmon L, Krasnov T, Ben-Asher E, Olender T, Khen M, Yaniv I, Zaizov R, Shalev H, Delaunay J, Fellous M, Lancet D, Beckmann JS: CatSper2, a human autosomal nonsyndromic male infertility gene. Eur J Hum Gen 2003, I I:497-502.
48. $\mathrm{Li} \mathrm{L}$, Liu JH: Changes in the expression of voltage-dependent $\mathrm{Ca}^{2+}$ channels in asthenospermia. Zhonghua Nan Ke Xue 2007, 13:706-709.

49. Redondo PC, Lajas Al, Salido GM, González A, Rosado JA, Pariente JA: Evidence for secretion-like coupling involving pp 60 src in the activation and maintenance of the store-operated $\mathrm{Ca}^{2+}$ entry in mouse pancreatic acinar cells. Biochem J 2003, 370:255-263.

50. Rosado JA, López JJ, Harper AGS, Harper MT, Redondo PC, Pariente JA, Sage SO, Salido GM: Two pathways for store-mediated calcium entry differentially dependent on the actin cytoskeleton in human platelets. J Biol Chem 2004, 279:2923I-29235.
Publish with Biomed Central and every scientist can read your work free of charge

"BioMed Central will be the most significant development for disseminating the results of biomedical research in our lifetime. "

Sir Paul Nurse, Cancer Research UK

Your research papers will be:

- available free of charge to the entire biomedical community

- peer reviewed and published immediately upon acceptance

- cited in PubMed and archived on PubMed Central

- yours - you keep the copyright 